\title{
Sexual Selection and Life History: Earlier Recalled Puberty Predicts Men's Phenotypic Masculinization
}

\author{
Leslie M. Doll ${ }^{1} \cdot$ Rodrigo A. Cárdenas ${ }^{2}$ • \\ Robert P. Burriss ${ }^{3}$ - David A. Puts ${ }^{1,4}$
}

Received: 23 March 2015 / Revised: 31 July 2015 / Accepted: 5 August 2015 /

Published online: 14 August 2015

C) Springer International Publishing 2015

\begin{abstract}
In some laboratory rodents, males' brains and behavior become less sensitive to the organizing effects of androgens across the time window surrounding puberty. Later puberty in human males has also been associated with less male-typical psychology and behavior, such as lower performance on mental rotation tasks and lower risk of substance abuse and delinquency. Here, we propose that life history (LH) theory provides a useful theoretical framework for understanding such relationships between pubertal timing and phenotypic masculinization. Because a faster male LH strategy emphasizes mating over parenting, earlier puberty may lead more generally to greater masculinization of traits that increase in sexual dimorphism at puberty and function in mating competition. In other words, we suggest that decreasing sensitivity to androgens represents a proximate mechanism that facilitates the development of mating-related adaptations in men with fast LH strategies. We tested this hypothesis in 153 men. Consistent with our hypothesis, earlier recalled pubertal timing predicted greater adult male body mass index, facial dominance, biceps circumference, and, to a lesser degree, systemizing and mental rotation ability. Some sexually dimorphic traits that were unrelated to pubertal timing in our data may have been less relevant to our male ancestors' mating success and hence to a fast LH strategy.
\end{abstract}

Keywords Androgens · Hormones $\cdot$ Life history $\cdot$ Pubertal timing $\cdot$ Sexual dimorphism Masculinity

David A. Puts

dap27@psu.edu

1 Department of Anthropology, Pennsylvania State University, 218 Carpenter Building, University Park, PA 16802, USA

2 Department of Psychology, Pennsylvania State University, University Park, PA 16802, USA

3 Department of Psychology, Northumbria University, Newcastle upon Tyne NE1 8ST, UK

4 Center for Brain, Behavior, and Cognition, Pennsylvania State University, University Park, PA 16802, USA 


\section{Introduction}

During puberty, elevated sex hormone concentrations promote sexual differentiation across a variety of human traits, including psychology and behavior (Sisk and Zehr 2005). Work with rodents has also revealed decreasing sensitivity with age to the organizational effects of peripubertal sex hormones on the brain and behavior (Schulz et al. 2009a; Schulz and Sisk 2006). If these time-dependent effects of hormone exposure are present in humans, then pubertal timing may also partly explain individual differences in sexually differentiated human psychobehavioral traits (Zehr et al. 2007).

Some evidence suggests that earlier puberty contributes to greater psychological sex typicality in humans. For example, men tend to outperform women at mental rotation tasks, and earlier puberty predicted better performance on such tasks among undergraduate men (Beltz and Berenbaum 2013). The absence of pubertal androgens due to hypogonadism, regardless of later androgen treatment, predicted poorer performance on a male-biased spatial task (Hier and Crowley 1982). Similarly, some studies have found that early-maturing males are at greater risk for substance abuse (Wichstrøm 2001) and delinquency (Felson and Haynie 2002; Negriff and Trickett 2010), both of which are more common among males (Canter 1982; Witt 2007).

Sexually differentiated traits such as facial masculinity, vocal masculinity, and muscularity are also influenced by pubertal testosterone (Seeman 2001; Seger and Thorstensson 2000), but few studies have examined their relationships with pubertal timing. Earlier puberty in males has been associated with higher adult body mass index (BMI, Mamun et al. 2009; Widen et al. 2012), which is slightly higher in men than in women (Lassek and Gaulin 2009). However, a high BMI could reflect either greater body fat or muscle mass, which are sexually dimorphic in opposite directions (Wells 2007), so this effect of pubertal timing on sex typicality remains unclear.

Thus, although evidence suggests that the expression of some sexually differentiated traits relates to the timing of pubertal sex hormone exposure, these associations have been explored for only a handful of traits. More importantly, we lack a functional hypothesis for why these associations might exist, and for predicting associations between pubertal timing and trait expression. Life history (LH) theory may provide a useful theoretical framework. LH theory addresses fundamental tradeoffs such as those between current and future reproduction, and between mating and parenting; resources utilized for one often cannot be used for the other (Stearns 1989; Del Giudice and Belsky 2011). Across species, high extrinsic mortality favors a fast LH strategy involving early reproduction, high fecundity with little investment in offspring, and rapid senescence. Slow LH species, such as humans, reproduce later, invest more in fewer offspring, and senesce more slowly.

LH strategies also vary within species, and individual differences in LH variables such as reproductive timing and senescence (Walker et al. 2006; Ellis et al. 2012) may be driven by exposure during early life to cues to extrinsic mortality risk (Wilson and Daly 1997; Ellis et al. 2012). Because high extrinsic mortality risk favors current reproduction over future reproduction, mortality risk may promote earlier puberty and thus earlier age at first copulation (Lam et al. 2002; Walker et al. 2006; Friedlander et al. 2007). While extrinsic mortality risk may promote earlier puberty, so too may nutritional state, which facilitates growth and attainment of reproductive maturity (Walker et al. 2006). In men, factors that shift development toward a fast LH 
strategy are also expected to influence the balance between mating and parenting, such that more resources are allocated to mating effort (Del Giudice and Belsky 2011). Indeed, in men but not women, earlier puberty has been found to predict greater sex drive, interest in casual sex, and reported number of lifetime sex partners (Ostovich and Sabini 2005). Because physical masculinity augments men's mating opportunities (Rhodes et al. 2005; Hodges-Simeon et al. 2011; Lassek and Gaulin 2009; Hill et al. 2013), variables that influence LH strategy, such as extrinsic mortality risk and nutrition, may also increase physical masculinity as a means of promoting mating success and earlier mating and reproduction. Moreover, if a fast LH strategy in men comprises a suite of traits that includes earlier puberty and greater mating effort (Del Giudice and Belsky 2011), then earlier pubertal timing should predict the expression of traits that aid in competition over mates - that is, traits favored by sexual selection.

LH theory thus offers an explanation for why the phenotype may be differentially responsive to sex hormones across the time window surrounding puberty, and why changes in responsiveness exhibit the observed patterns. For instance, mental rotation abilities assist with spatial awareness and navigation and thus may have helped ancestral men win mates through enhanced mate location (Miner et al. 2014; Gaulin 1992) and targeting of same-sex competitors (Puts 2010) and/or prey items used to obtain mates (Hawkes 1990). Thus, conditions promoting a fast LH strategy including earlier puberty might also promote enhanced spatial cognitive abilities. Likewise, risk taking may be functional to mating success in fast LH individuals (Daly and Wilson 1988; Baker and Maner 2009), and an increase in this trait with earlier puberty may be reflected in higher rates of delinquency and substance abuse (Wills et al. 1994).

In the current study, we examined whether earlier pubertal timing positively predicts the expression of putative sexually selected traits that develop under the influence of pubertal androgens. Because research has shown that men's muscularity, strength, and facial and vocal characteristics are especially likely to have been targets of sexual selection (Hill et al. 2013; Lassek and Gaulin 2009; Doll et al. 2014), we focused on these traits. We also attempted to replicate previous associations with mental rotation ability (Beltz and Berenbaum 2013) and BMI (Mamun et al. 2009; Widen et al. 2012).

We also measured the empathizing quotient (Wakabayashi et al. 2006) and the "reading the mind in the eyes" test (Baron-Cohen et al. 2001), both of which measure psychological traits related to care giving and prosociality, and render lower scores in males and in autistic individuals of either sex (Baron-Cohen et al. 2003; Baron-Cohen and Wheelwright 2004; Auyeung et al. 2009a, b, 2012; Chapman et al. 2006; Buss and Perry 1992). On the one hand, if sex differences in empathy and prosociality depend in part on pubertal androgens, then one might predict that earlier puberty would relate to more masculine scores on these tests. This would apply particularly if lower empathy and prosociality are related to less investment in mates and offspring and greater mating effort - that is, to a fast LH strategy. On the other hand, some evidence has linked autistic-like traits to a relative disinterest in short-term mating, higher investment in a partner, and greater commitment to long-term relationships - that is, to a slow LH strategy (Del Giudice et al. 2010, 2014). Consequently, one might instead predict that earlier puberty would relate to less masculine scores on these measures (i.e., greater empathizing, better performance on the eyes test).

Finally, we measured physical aggression and systemizing, which show a male bias and have putatively been shaped by sexual selection, but for which there is either no 
evidence or negative evidence for an increase in sexual dimorphism over puberty. Although men likely evolved a greater propensity for physical aggression because it contributed to mating success in some ancestral contexts (Archer 2009), sex differences in physical aggression have been found not to increase at puberty (Finkelstein et al. 1994; Archer 2004; Tremblay et al. 1998). Systemizing refers to a person's drive to analyze or construct repeating, lawful patterns and shows a male bias (Baron-Cohen 2003). Systemizing is hypothesized to be related to abilities such as pursuing status in dominance hierarchies, manufacturing weapons and tools, and spatial navigation, all of which may have been important for men's mating success over human evolutionary history (Baron-Cohen 2003, 2008). However, the male bias is present in children at least by age six to nine (Auyeung et al. 2006), and no evidence of which we are aware indicates that the sex difference increases at puberty.

\section{Methods}

\section{Participants}

Participants were 153 men (mean age $=20.1 \pm 1.8$ year) from a large Midwestern U.S. university, selected from the 176 participants reported in Puts et al. (2012a) on the basis of having provided data on pubertal timing. Five hundred sixty-eight male raters (mean age: $19.4 \pm 1.8$ year) were recruited from a large northeastern U.S. university to rate facial photographs and voice recordings of the male participants. The universities' Institutional Review Boards approved this study.

\section{Pubertal Timing}

To measure pubertal timing, the Pubertal Development Scale (PDS) (Petersen et al. 1988) was modified so that it could be answered retrospectively. For example, participants were asked, "Do you think you began growing facial hair and shaving any earlier or later than most other boys?" For all questions, participants were given five answer options ranging from "much earlier" to "much later," and a sixth option of "don't know." In addition to facial hair, participants reported on relative timing of voice change, growth spurt, body hair growth, skin changes, spontaneous erections, wet dreams, and development in general (Table 1). We used PDS items targeting relative pubertal timing rather than absolute timing (age or grade in school) because previous work has shown that perceptions of relative timing correlate highly with absolute timing, and because participants can better recall the timing of events relative to peers (reviewed in Beltz and Berenbaum 2013).

\section{Physiological Measures}

For body mass index (BMI; $\mathrm{kg} / \mathrm{m}^{2}$ ), height was obtained with a meter stick affixed to a wall, and weight with an electronic scale. Right- and left-hand strengths were measured using a JAMAR hydraulic hand dynamometer. We used a tailor's tape to measure the circumference of participants' right and left flexed biceps at the widest 
Table 1 Descriptive statistics

\begin{tabular}{llll}
\hline & $N$ & Mean & St Dev \\
\hline Puberty items & & & \\
General development & 152 & 3.2 & 0.9 \\
Facial hair & 153 & 3.3 & 1.2 \\
Voice drop & 148 & 3.0 & 0.9 \\
Growth spurt & 149 & 3.0 & 1.0 \\
Body hair & 145 & 3.0 & 0.7 \\
Acne & 150 & 3.1 & 0.8 \\
Spontaneous erections & 113 & 2.8 & 0.6 \\
Wet dreams & 84 & 3.2 & 0.7 \\
Outcome traits & & & \\
Height (m) & 153 & 178.6 & 7.1 \\
Weight (kg) & 153 & 78.7 & 13.9 \\
BMI & 153 & 24.6 & 4.0 \\
Biceps circumference $(\mathrm{cm})$ & 153 & 33.5 & 3.3 \\
Hand strength (kg) & 153 & 49.1 & 8.0 \\
Facial dominance & 137 & 3.7 & 0.8 \\
Vocal dominance & 146 & 3.6 & 0.8 \\
Physical aggression & 152 & 21.6 & 6.9 \\
Mental rotations & 153 & 13.5 & 4.4 \\
Systemizing quotient & 151 & 25.0 & 8.5 \\
Empathizing quotient & 151 & 22.3 & 6.8 \\
Eyes test & 153 & 26.1 & 3.8 \\
\hline
\end{tabular}

points (see Table 1 for descriptive statistics). Flexed biceps circumference and hand strength are strong predictors of upper body strength (Sell et al. 2010); for example, flexed biceps circumference accounts for approximately $50 \%$ of the variation in upper body lifting ability (Sell et al. 2009).

For facial photographs, a tripod-mounted Canon PowerShotS10 digital camera was placed approximately $1 \mathrm{~m}$ away from participants, with the height of the camera adjusted for each participant. Constant lighting was used for all photographs. Participants were instructed to remove makeup, glasses, and facial piercings, and they were asked to use headbands if hair obscured any part of their faces. Participants maintained relaxed, neutral expressions for the facial photographs. Images were cropped below the chin, interpupillary distance was normalized, and images were rotated so that both pupils lay on the same horizontal axis.

A Shure SM58 vocal cardioid microphone was used to record participants reading the first six sentences of the Rainbow Passage (Fairbanks 1960), a passage developed for vocal drills, in an anechoic, soundproof booth. The microphone was kept approximately $9.5 \mathrm{~cm}$ from the participants' mouths by a curved wire projection. Voices were recorded in mono at a sampling rate of $44,100 \mathrm{~Hz}$ using Goldwave software and saved as .wav files. 
Using a 7-point Likert scale, raters assessed the dominance of randomly ordered facial photographs and randomly ordered voice recordings by answering how likely they thought each male was to win a fight with an average male undergraduate. Perceived physical dominance in men's faces and voices is strongly related to objectively measured physical masculinity (Puts et al. 2012b), but is likely a more sensitive measure than facial masculinity assessed from distances between a limited number of landmarks, or vocal masculinity assessed from one or a few acoustic parameters. Only the first sentence of the Rainbow Passage was used in order to minimize rater fatigue. No rater evaluated a photograph or recording of a particular individual more than once. Each stimulus was rated at least 15 times, and the first 15 ratings obtained were averaged to produce a dominance rating for each face and voice (Table 1).

Facial photographs, voice recordings, and biometric measurements were collected twice at separate sessions 1 week apart. Measurements and dominance ratings correlated highly across sessions $(.99 \geq r>.75$, all $p<.0001)$, and were thus averaged. Because mean left and right measurements for both hand strength $(r=.84, p<.0001)$ and biceps circumference $(r=.95, p<.0001)$ were also highly correlated, they were averaged for each measure.

\section{Psychological Measures}

All psychometric instruments were administered via computer. The 3D Mental Rotation Task (MRT), which consists of two 4-min sections of 10 items each, was used to assess participants' spatial abilities (Vandenberg and Kuse 1978). For this task, participants viewed line drawings of 3-dimensional block figures. One line drawing (target) was presented with four similar figures, and participants were instructed to choose the two rotated figures that matched the target. As per Voyer and colleagues (1995), participants received one point for each item if both correct answers were chosen.

Physical aggression was measured using the physical aggression subscale of the Aggression Questionnaire (Buss and Perry 1992). This subscale includes nine questions such as, "Once in a while I can't control the urge to strike another person," "If somebody hits me, I hit back," and "If I have to resort to violence to protect my rights, I will." Participants answered on a 5-point scale with options ranging from "extremely uncharacteristic of me" to "extremely characteristic of me". After one item was reverse scored, scores on individual items were summed to produce an overall score for the subscale.

Participants completed the SQ-Short and EQ-Short scales for assessing systemizing (propensity to analyze or construct systems) and empathizing (ability to read others' mental states), respectively (Wakabayashi et al. 2006; Baron-Cohen and Wheelwright 2004; Baron-Cohen et al. 2003). The SQ-Short comprises 25 questions such as "I am fascinated by how machines work", and the EQ-Short comprises 22 questions such as "I can easily tell if someone else wants to enter a conversation" to which participants answer whether they agree or disagree. Approximately half of the items on each scale are reverse scored, and items are then summed separately for systemizing and empathizing subscales.

Finally, participants completed Baron-Cohen et al.'s (2001) revised "reading the mind in the eyes task" (hereafter referred to as the eyes task), which measures ability to 
assess others' emotions. For each item, participants viewed a photo cropped around the eyes of a face expressing an emotion, along with four words describing emotions, and chose the word that best described the emotion depicted. Items for which a participant correctly identified the depicted emotion were tallied to produce an overall score.

\section{Data Treatment and Statistical Analysis}

To correct skew, eyes task and mental rotation scores were squared, and the log of BMI was taken. Given the large number of predictor and outcome variables, and to reduce the risk of Type I error, we conducted separate principal components analyses (PCA) on a) the revised PDS questions and b) on all outcome variables. We used oblimin rotation, replacing missing values with means for each variable, and saved PCs with eigenvalues $>1$ as variables.

All PDS questions except for wet dreams and spontaneous erections loaded heavily (component loadings>.6) onto PC1 ("Pubertal Timing") (Table 2). Spontaneous erections loaded heavily onto PC2 (correlation of PC2 with PC1: $r_{153}=.10, p=.231$ ). These loadings mirror previous findings in that onset of wet dreams fail to load onto the primary pubertal timing component (Beltz and Berenbaum 2013). One reason for this inconsistency may be that men do not remember the timing of the onset of wet dreams and spontaneous erections relative to peers because they occur privately. Indeed, men often answered, "don't know" for the timing of wet dreams (69/153) and spontaneous erections (40/153), far more frequently than for other items (0-8/153). We therefore used PC1 for all pubertal timing analyses. Internal consistency on PDS items was good (items loading strongly onto PC1: Cronbach's $\alpha=.83$; all items: Cronbach's $\alpha=.78$ ).

For the PCA conducted on the outcome measures (Table 3), BMI, biceps circumference, facial dominance, and systemizing quotient loaded heavily onto PC1 (loadings $>.49$ ); the eyes task, mental rotations, and the empathizing quotient loaded most heavily onto PC2; and vocal dominance, physical aggression, and strength loaded most heavily onto PC3. Correlations between components were PC1 and PC2: $r_{153}=.09$, $p=.287$; PC1 and PC3: $r_{153}=.13, p=.123$; PC2 and PC3: $r_{153}=-.09, p=.246$.

Table 2 Pattern loadings for PCA performed on revised PDS questions

\begin{tabular}{lll}
\hline & $\begin{array}{l}\text { Puberty PC1 } \\
\mathrm{EV}=3.4,\end{array}$ & $\begin{array}{l}\text { Puberty PC2 } \\
42.2 \%^{\mathrm{a}}\end{array}$ \\
\hline GVeneral development & $\mathbf{. 8 2}$ & $13.4 \%^{\mathrm{a}}$ \\
Body hair & $\mathbf{. 7 8 6}$ & .223 \\
Acne & $\mathbf{. 7 1 9}$ & -.018 \\
Facial hair/shaving & $\mathbf{. 7 1 9}$ & -.296 \\
Voice dropping & $\mathbf{. 6 9 7}$ & -.040 \\
Growth spurt & $\mathbf{. 6 2 1}$ & .207 \\
Wet dreams & .054 & -.097 \\
Spontaneous erections & .393 & $\mathbf{9 5 3}$ \\
\hline
\end{tabular}

\footnotetext{
${ }^{a}$ Percentages refer to the amount of variance explained
}

Bolded loadings reflect variables considered to characterize the PC in each column 
Table 3 Component loadings for PCA performed on outcome variables

\begin{tabular}{llll}
\hline & Trait PC1 & Trait PC2 & Trait PC3 \\
EV=2.5, & $\begin{array}{l}\text { EV }=1.5, \\
15.1 \%{ }^{\mathrm{a}}\end{array}$ & $\begin{array}{l}\text { EV=1.2, } \\
12.1 \%{ }^{\mathrm{a}}\end{array}$ \\
\hline BMI & $\mathbf{. 8 3 0}$ & .014 & .116 \\
Biceps circumference & $\mathbf{. 8 2 3}$ & -.011 & .416 \\
SQ & $\mathbf{4 9 5}$ & .237 & -.176 \\
Facial dominance & $\mathbf{4 9 3}$ & -.317 & .326 \\
Eyes test & -.124 & $\mathbf{. 7 2 3}$ & .105 \\
Mental rotations & .135 & $\mathbf{. 6 4 7}$ & -.051 \\
EQ & .391 & $\mathbf{. 5 3 9}$ & -.238 \\
Vocal dominance & -.005 & .022 & $\mathbf{. 7 3 6}$ \\
Physical aggression & .195 & -.138 & $\mathbf{. 6 6 9}$ \\
Hand strength & .450 & .270 & $\mathbf{. 4 9 8}$ \\
\hline
\end{tabular}

\footnotetext{
${ }^{\mathrm{a}}$ Percentages refer to the amount of variance explained
}

Bolded loadings reflect variables considered to characterize the PC in each column

Pearson correlations were used to test pubertal timing relationships and for post hoc exploration of individual variables. All tests were two-tailed and considered significant if $p<.05$.

\section{Results}

Pubertal timing significantly predicted trait PC1 $\left(r_{153}=-.38, p<.0001\right.$, Fig. 1a), but not PC2 $\left(r_{153}=-.07, p=.39\right)$ or PC3 $\left(r_{153}=.08, p=.33\right)$. Post hoc analyses (Table 4) revealed significant negative correlations (earlier puberty associated with greater masculinity) between pubertal timing and all variables that loaded $>.49$ onto PC1: BMI $\left(r_{153}=-.30, p<.001\right.$, Fig. 1b), biceps circumference $\left(r_{153}=-.32, p<.0001\right.$, Fig. $\left.1 \mathrm{c}\right)$, facial dominance $\left(r_{137}=-.26, p=.002\right.$, Fig. $\left.1 \mathrm{~d}\right)$, and SQ $\left(r_{151}=-.17, p=.04\right)$.

In order to explore whether the relationship between pubertal timing and muscularity remained significant after controlling for BMI, we ran a multiple regression in which both BMI and biceps size were used to predict pubertal timing. In this model, biceps circumference was a significant predictor $(\beta=-.23, p=.03, \mathrm{VIF}=1.83)$, BMI was not $(\beta=-.08, p=.44, \mathrm{VIF}=1.94)$, and the interaction term of BMI and biceps circumference $(\beta=-.18, p=.03, \mathrm{VIF}=1.09)$ was also significant. Because the interaction term was significant, we could not drop it from the model and consider only the main effects. To explore this interaction, we regressed pubertal timing on biceps size only for observations either one standard deviation above the mean of BMI or one standard deviation below the mean of BMI. There was a significant inverse relationship between pubertal timing and biceps size only with higher BMI measurements $(\beta=-.69, p<.001)$. In other words, larger biceps predicted earlier puberty only in men with a higher BMI.

Although the PC with a high loading from mental rotation ability did not exhibit a significant relationship with pubertal timing, we attempted to replicate a previous 


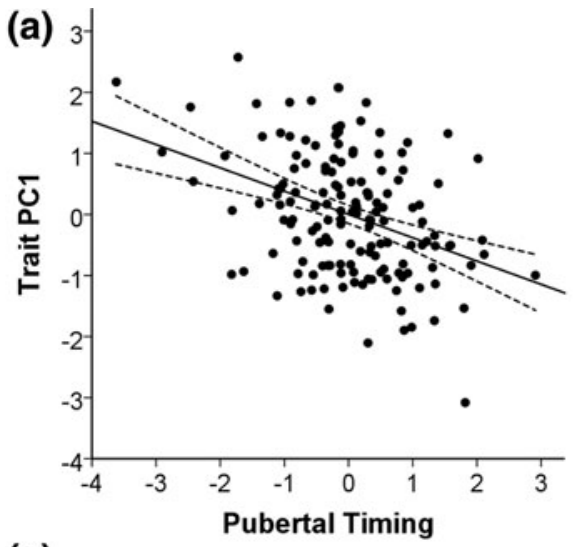

(c)

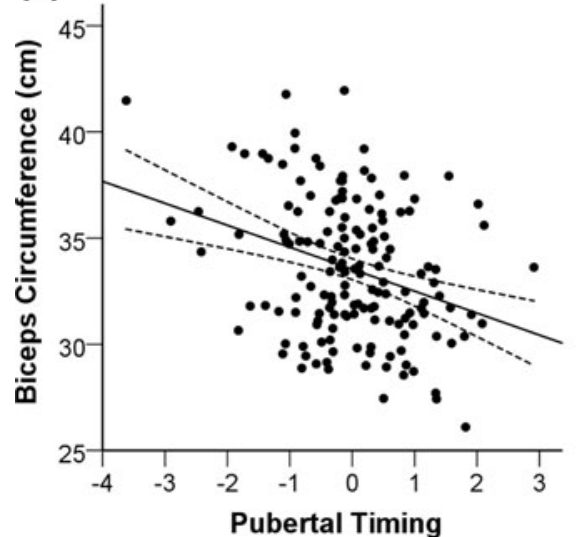

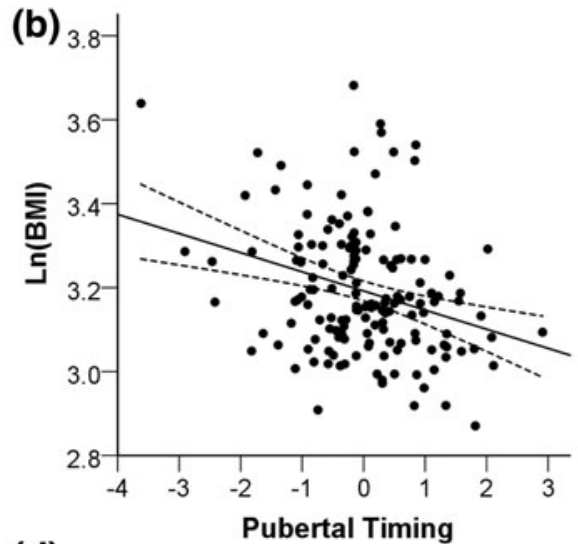

(d)

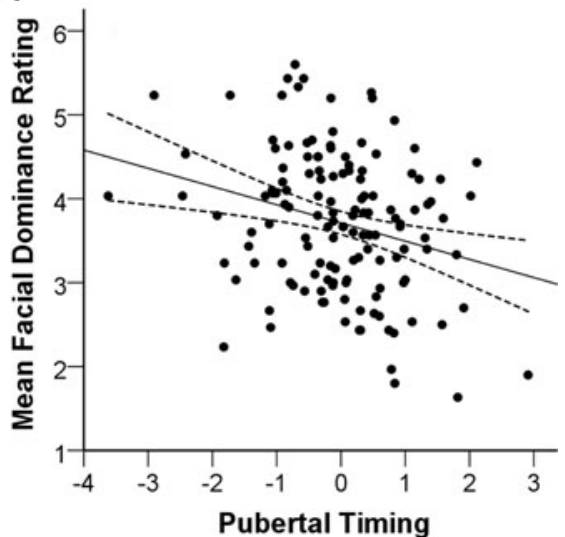

Fig. 1 Relationships between pubertal timing and putative sexually selected traits in men (least-squares regression line and $95 \% \mathrm{CI}$ )

Table 4 Zero-order correlations between pubertal timing (Pub. PC1) and raw outcome variables

\begin{tabular}{|c|c|c|c|c|c|c|c|c|c|c|}
\hline & 2. & 3. & 4. & 5. & 6. & 7. & 8. & 9. & 10. & 11. \\
\hline 1. Pub. timing & $-.30 * * *$ & $-.32 * * *$ & $-.17 *$ & $-.26 * *$ & .02 & -.14 & $-.18^{*}$ & .06 & .09 & -.05 \\
\hline 2. BMI & & $.70^{* * *}$ & $.24 * *$ & $.30 * * *$ & -.03 & .02 & $.24 * *$ & .04 & $.16^{*}$ & $.22 * *$ \\
\hline 3. Biceps & & & $.16^{*}$ & $.44 * * *$ & -.06 & .10 & $.16^{*}$ & $.17^{*}$ & $.36^{* * *}$ & $.40 * * *$ \\
\hline 4. SQ & & & & .10 & -.01 & .15 & .14 & -.04 & .03 & $.19 *$ \\
\hline \multicolumn{3}{|c|}{ 5. Facial dominance } & & & -.16 & -.06 & -.02 & $.20^{*}$ & .10 & $.20 *$ \\
\hline \multicolumn{3}{|c|}{ 6. Eyes test } & & & & $.21 * *$ & $.22 * *$ & .05 & .02 & .04 \\
\hline \multicolumn{3}{|c|}{ 7. Mental rotations } & & & & & .10 & -.00 & -.12 & $.16^{*}$ \\
\hline \multicolumn{3}{|c|}{ 8. EQ } & & & & & & -.06 & -.10 & .14 \\
\hline \multicolumn{3}{|c|}{ 9. Vocal dominance } & & & & & & & $.20 *$ & $.22 * *$ \\
\hline \multicolumn{3}{|c|}{ 10. Physical aggression } & & & & & & & & $.24 * *$ \\
\hline \multicolumn{2}{|c|}{ 11. Hand strength } & & & & & & & & & \\
\hline
\end{tabular}

${ }^{*} p<.05, * * p<.01, * * * p<.001$ 
finding that earlier puberty was associated with better performance on mental rotation tasks (Beltz and Berenbaum 2013). We found that the correlation between pubertal timing and mental rotation performance was indeed negative and marginally statistically significant $\left(r_{153}=-.14, p=.07\right.$; Table 4$)$.

Quadratic regressions of all outcome measures and associated PCs on pubertal timing revealed no significant curvilinear relationships (all $p>.27$ ).

\section{Discussion}

Our study is the first of which we are aware to show that earlier puberty predicted higher facial dominance, biceps circumference, and systemizing in young adult men. Each of these traits was related to puberty in the predicted direction: earlier puberty was associated with greater masculinity. Compared to facial dominance and biceps' circumference, the effect of pubertal timing on systemizing was relatively small $\left(r_{151}=\right.$ -.17). Because systemizing is sexually dimorphic before puberty (Auyeung et al. 2006), pubertal timing may have a smaller effect on systemizing than it does on traits that develop the majority of their dimorphism at puberty.

Working from the perspective of life history theory, we suggest that masculine facial morphology, muscularity, and perhaps systemizing are associated with pubertal timing because they assist with men's mating success. Life history theory offers a framework to explain relationships between pubertal timing and the expression of some sexually differentiated traits. For males, fast strategists should enter puberty earlier and develop greater masculinity in traits that augment mating success as opposed to parental investment.

We replicated previous findings that earlier pubertal timing is associated with higher adult BMI (Kindblom et al. 2006; Mamun et al. 2009; Widen et al. 2012) (Fig. 1b). The association of BMI with earlier puberty may be due to increased muscle mass in men who experienced earlier pubertal development. High BMI may reflect the acquisition of sufficient somatic resources to enter into mating competition, but those who reap mating benefits when young may experience later health problems related to increased adiposity. That earlier puberty also predicted biceps circumference for men with high BMI in our study suggests that men who go through puberty earlier also develop more muscle. These results may explain the previous association of earlier puberty with increased bone mineral density (BMD) (Gilsanz et al. 2011), given that muscle strength (Snow-Harter et al. 1992) and body mass (Felson et al. 1993) are known to increase BMD. We did not find a relationship between hand strength and pubertal timing, even though both biceps circumference and hand strength were intended to be proxies of overall upper body strength. It is possible that pubertal timing affects some muscle groups more than others. Future studies should explore these possibilities.

The lack of a relationship between pubertal timing and the PC onto which vocal dominance loaded was unexpected, as evidence indicates that voices have been shaped by sexual selection and contribute to men's dominance and mating success (Puts et al. 2006, 2007, 2012a; Hodges-Simeon et al. 2011; Wolff and Puts 2010). In addition, pubertal hormones influence vocal anatomy and acoustic parameters that contribute to perceptions of men's dominance (Fitch and Giedd 1999; Newman et al. 2000; Harries 
et al. 1998; Hollien et al. 1994; Titze 2000; Hodges-Simeon et al. 2013, 2014). One possible explanation is that vocal dominance depends on other factors that are not discretely organized around puberty and/or remain flexible in adulthood. For example, acoustic parameters such as fundamental frequency may be modified situationally in relation to relative dominance (Puts et al. 2006) or courtship (Leongómez et al. 2014; Weusthoff et al. 2013). Moreover, the cost of reorganizing soft vocal tissue (e.g., vocal fold thickness) may be lower than the cost of reorganizing other competitive traits such as facial skeletal tissue, and thus vocal tissue may not experience a strong decline in sensitivity to androgens around puberty. Indeed, vocal fundamental frequency responds to hormonal treatment in adulthood (Borsel et al. 2000).

The lack of a relationship between pubertal timing and the PC onto which physical aggression loaded was consistent with previous research showing that sex differences in physical aggression occur prior to puberty (Archer 2004). At first glance, this lack of a relationship appears to conflict with the fact that delinquent behaviors are known to exhibit a negative relationship with pubertal timing. However, the relationship between pubertal timing and delinquency may be driven by nonviolent psychological traits, such as internalizing, and nonviolent behaviors such as theft (Felson and Haynie 2002).

In contrast with positive evidence for associations between earlier puberty and some traits related to mating competition, associations between pubertal timing and traits potentially related to investment in mates and offspring were equivocal at best. The PC with high loadings from empathizing and reading others' emotional states was not significantly associated with pubertal timing. However, higher empathizing scores were associated with earlier puberty in zero-order correlations. Although this comports with the hypothesis that autistic-like traits are associated with a slow LH strategy (Del Giudice et al. 2010, 2014), the association would not survive correction for multiple statistical testing, performance on the eyes test was unrelated to pubertal timing, and systemizing was related to puberty in the opposite direction: less autistic-like performance (Auyeung et al. 2009b) was associated with earlier puberty.

Taken together, these results suggest that more masculine trait expression in men may be related to earlier pubertal timing if the trait is (a) important to men's mating success and (b) develops under the influence of pubertal androgens. Our results further suggest that men's traits are more likely to be related to pubertal timing if they are costly to change and are therefore relatively unresponsive to androgens in adulthood.

There may be an adaptive logic to these patterns: In men, factors favoring a faster LH strategy, such as more cues to extrinsic mortality risk and better nutritional status during childhood, should not only promote earlier sexual maturation but also the development of other traits useful in obtaining mates. At the same time, not all men are equally likely to benefit from enhanced mating effort. In a competitive mating arena, many men will fail to achieve high mating success and may more profitably direct their reproductive effort toward guarding and investing in a single mate and their mutual offspring. Men's reproductive strategy should thus be contingent, with males in better condition (e.g., due to abundant nutrition during development or high quality genes) and able to develop intrasexually competitive phenotypes tending to adopt a more mating-oriented reproductive strategy (Gangestad and Simpson 2000) that may include earlier sexual maturation. Declining sensitivity to peripubertal androgens in some secondary sex traits (Schulz and Sisk 2006; Zehr et al. 2007) may thus represent the proximate mechanism underlying these adaptive developmental contingencies. 


\section{Limitations}

One limitation of this study was that pubertal timing was assessed retrospectively, so our data are subject to participants' imperfect recollections. Agreement between selfreport measures and physician reports typically exhibits low to moderate kappa values but moderate to high correlation values (Dorn et al. 2006). For the PDS specifically, Shirtcliff and colleagues (2009) report a kappa value of .36 and correlations between .65 and .77. Despite this added noise, however, there were significant (including some highly significant) relationships between pubertal timing and several outcome variables. One might expect stronger effects with less noisy measures of development.

Additionally, because of the retrospective and correlational nature of this study, we are unable to establish the direction of causality. Indeed, as noted above, some evidence indicates that childhood BMI may influence pubertal timing (Ahmed et al. 2009), although the causal relationship between pubertal timing and BMI may also be bidirectional. We used life history theory to predict some previously unknown associations between pubertal timing and trait expression, and drawing on experimental laboratory animal research and correlational human research, we hypothesized that some of these associations result from decreased sensitivity to pubertal androgens. However, without additional data such as longitudinal hormonal data, we cannot in fact specify the mechanism linking pubertal timing to the expression of sexually dimorphic traits. Our novel findings thus represent a first approach to be expanded on by future research.

\section{Future Research}

Future longitudinal studies would allow for explorations of possible interactions between pubertal timing, early environment, and genes or brain development; the ability to control for variables such as childhood BMI; and the measurement of pubertal hormones and their relationships with the traits examined in this study. A particularly important future direction is to test whether extrinsic mortality risk and nutritional state predict the development of secondary sex traits in men, and if these relationships are mediated by pubertal timing. Another important future direction involves examining whether masculinity in the traits under study contribute uniquely to mating efforts earlier in life. For example, such a study could test if more masculinized faces increase mating success in younger males more than they do in older males.

\section{Conclusions}

This study expands on the work of and Sisk and colleagues (Schulz and Sisk 2006; Schulz et al. 2009a, b; Zehr et al. 2007) and Beltz and Berenbaum (2013) in exploring the organizing effects of hormones during puberty, and further emphasizes that pubertal timing may influence the masculinization of diverse adult traits. Pubertal timing explained a modest amount of the variance (approximately $10 \%$ ) in adult male BMI, facial dominance, and biceps circumference, as well as a smaller proportion of the variance in systemizing and mental rotation ability. Decreasing sensitivity to steroids (Schulz and Sisk 2006; Zehr et al. 2007) is a plausible proximate mechanism for the negative relationships between the masculinity of the traits in the current study and 
pubertal timing. These results thus suggest that traits such as facial dominance, muscularity, and systemizing may experience decreasing sensitivity to organizational effects in adolescence. Importantly, this study illustrates how adaptive reasoning may help clarify relationships between the timing of pubertal androgen exposure and the development of diverse anthropometric and psychological traits.

Acknowledgments This work is supported by the National Science Foundation Graduate Research Fellowship under Grant No. (DGE1255832).

\section{References}

Ahmed, M. L., Ong, K. K., \& Dunger, D. B. (2009). Childhood obesity and the timing of puberty. Trends in Endocrinology and Metabolism, 20(5), 237-242.

Archer, J. (2004). Sex differences in aggression in real-world settings: a meta-analytic review. Review of General Psychology, 4, 291-322. doi:10.1037/1089-2680.8.4.291.

Archer, J. (2009). Does sexual selection explain human sex differences in aggression? Behavioral and Brain Sciences, 32(3-4), 249-266.

Auyeung, B., Baron-Cohen, S., Chapman, E., Knickmeyer, R., Taylor, K., \& Hackett, G. (2006). Foetal testosterone and the child systemizing quotient. European Journal of Endocrinology, 155, 123-130.

Auyeung, B., Baron-Cohen, S., Ashwin, E., Knickmeyer, R., Taylor, K., Hackett, G., et al. (2009a). Fetal testosterone predicts sexually differentiated childhood behavior in girls and in boys. Psychological Science, 20(2), 144-148.

Auyeung, B., Wheelwright, S., Allison, C., Atkinson, M., Samarawickrema, N., \& Baron-Cohen, S. (2009b). The children's empathy quotient and systemizing quotient: sex differences in typical development and in autism spectrum conditions. Journal of Autism and Developmental Disorders, 39(11), 1509-1521.

Auyeung, B., Allison, C., Wheelwright, S., \& Baron-Cohen, S. (2012). Brief report: development of the adolescent empathy and systemizing quotients. Journal of Autism and Developmental Disorders, 42(10), 2225-2235. doi:10.1007/s10803-012-1454-7.

Baker, M. D., Jr., \& Maner, J. K. (2009). Male risk-taking as a context-sensitive signaling device. Journal of Experimental Social Psychology, 45(5), 1136-1139. doi:10.1016/j.jesp.2009.06.006.

Baron-Cohen, S. (2003). The essential difference: Male and female brains and the truth about autism. New York: Basic Books.

Baron-Cohen, S. (2008). Autism, hypersystemizing, and truth. The Quarterly Journal of Experimental Psychology, 61(1), 64-75. doi:10.1080/17470210701508749.

Baron-Cohen, S., \& Wheelwright, S. (2004). The empathy quotient: an investigation of adults with asperger syndrome or high cuntioning autism, and normal sex differences. Journal of Autism and Developmental Disorders, 34(2), 163-175.

Baron-Cohen, S., Wheelwright, S., Hill, J., Raste, Y., \& Plumb, I. (2001). The "reading the mind int he eyes" test revised version: a study with normal adults, and adults with asperger syndrome or high-functioning autism. Journal of Child Psychology and Psychiatry, and Allied Disciplines, 42, 241-251.

Baron-Cohen, S., Richler, J., Bisarya, D., Gurunathan, N., \& Wheelwright, S. (2003). The systemizing quotient: an investigation of adults with Asperger syndrome or high-functioning autsm, and normal sex differences. Philosophical Transactions: Biological Sciences, 358, 361-374.

Beltz, A. M., \& Berenbaum, S. A. (2013). Cognitive effects of variations in pubertal timing: is puberty a period of organization for human sex-typed cognition? Hormones and Behavior, 63, 823-828. doi:10. 1016/j.yhbeh.2013.04.002.

Borsel, J. V., Cuypere, G. D., Rubens, R., \& Destaerke, B. (2000). Voice problems in female-to-mal transsexuals. International Journal of Language \& Communication Disorders, 35(3), 427-442.

Buss, A. H., \& Perry, M. (1992). The aggression questionnaire. Journal of Personality and Social Psychology, 63(3), 452-459.

Canter, R. J. (1982). Sex differences in self-report delinquency. Criminology, 20(3-4), 373-394. doi:10.1111/j. 1745-9125.1982.tb00467.x. 
Chapman, E., Baron-Cohen, S., Auyeung, B., Knickmeyer, R., Taylor, K., \& Hackett, G. (2006). Fetal testosterone and empathy: evidence from he empathy quoteint (EQ) and the "reading the mInd in the eyes" test. Social Neuroscience, 1(2), 135-148.

Daly, M., \& Wilson, M. (1988). Homicide. New York: Aldine de Gruyter.

Del Giudice, M., \& Belsky, J. (2011). The development of life history strategies: Toward a multi-stage theory. In D. M. Buss \& P. H. Hawley (Eds.), The evolution of personality and individual differences (pp. 154 176). New York: Oxford University Press.

Del Giudice, M., Angeleri, R., Brizio, A., \& Elena, M. R. (2010). The evolution of autistic-like and schizotypal traits: a sexual selection hypothesis. Frontiers in Psychology, 1, 1-18.

Del Giudice, M., Klimczuk, A. C. E., Traficonte, D. M., \& Maestripieri, D. (2014). Autistic-like and schizotypal traits in a life history perspective: diametrical associations with impulsivity, sensation seeking, and sociosexual behavior. Evolution and Human Behavior, 35, 415-424.

Doll, L. M., Hill, A. K., Cárdenas, R. A., Welling, L. L. M., Wheatley, J. R., \& Puts, D. A. (2014). How well do men's faces and voices index mate quality and dominance? Human Nature, 25(2), 200-212.

Dorn, L. D., Dahl, R. E., Woodward, H. R., \& Biro, F. (2006). Defining the boundaires of early adolescence: a uder's guide to assessing pubertal status and pubertal timing in research with adolescents. Applied Developmental Science, 10(1), 30-56.

Ellis, B. J., Shirtcliff, E. A., Boyce, W. T., Deardorff, J., \& Essex, M. J. (2012). Quality of early family relationships and the timing and tempo of puberty: effects depend on biological sensitivity to context. Development and Psychopathology, 23(1), 85-99.

Fairbanks, G. (1960). Voice and articulation drillbook (2nd ed.). New York: Harper \& Row.

Felson, R. B., \& Haynie, D. L. (2002). Pubertal development, social factors, and delinquency among adolescent boys. Criminology, 40(4), 967-988.

Felson, D. T., Zhang, Y., Hannan, M. T., \& Anderson, J. J. (1993). Effects of weight and body mass index on bone mineral density in men and women: the Framingham study. Journal of Bone and Mineral Research, $8,567-573$.

Finkelstein, J. W., Eye, A. V., \& Preece, M. A. (1994). The relationship ebtween aggressive behavior and puberty in normal adolescents: a longitudinal study. Journal of Adolescent Health, 15(4), 319-326.

Fitch, W. T., \& Giedd, J. (1999). Morphology and development of the human vocal tract: a study using magnetic resonance imaging. Journal of the Acoustical Society of America, $106(3 \mathrm{Pt}$ 1), 1511-1522.

Friedlander, L. J., Connolly, J. A., Pepler, D. J., \& Craig, W. M. (2007). Biological, familial, and peer influences on dating in early adolescence. Archives of Sexual Behavior, 36, 821-830. doi:10.1007/ s10508-006-9130-7.

Gangestad, S. W., \& Simpson, J. A. (2000). On the evolutionary psychology of human mating: trade-offs and strategic pluralism. Behavioral and Brain Sciences, 23, 573-587.

Gaulin, S. J. C. (1992). Evolution of sex differences in spatial ability. Yearbook of Physical Anthropology, 35, $125-151$.

Gilsanz, V., Chalfant, J., Kalkwarf, H., Zemel, B., Lappe, J., Oberfield, S., et al. (2011). Age at onset of puberty predicts bone mass in young adulthood. Journal of Pediatrics, 158, 100-105. 105 e101-102.

Harries, M., Hawkins, S., Hacking, J., \& Hughes, I. (1998). Changes in the male voice at puberty: vocal fold length and its relationship to the fundamental frequency of the voice. Journal of Laryngology and Otology, 112(5), 451-454.

Hawkes, K. (1990). Why do men hunt? Benefits for risky choices. In E. Cashdan (Ed.), Risk and uncertainty in tribal and peasant economies (pp. 146-166). Boulder: Westview Press.

Hier, D. B., \& Crowley, W. F., Jr. (1982). Spatial ability in androgen-deficient men. The New England Journal of Medicine, 306(20), 1202-1205.

Hill, A. K., Hunt, J., Welling, L. L. M., Cárdenas, R. A., Rotella, M. A., Wheatley, J. R., et al. (2013). Quantifying the strength and form of sexual selection on men's traits. Evolution and Human Behavior, 34, 334-341. doi:10.1016/j.evolhumbehav.2013.05.004.

Hodges-Simeon, C. R., Gaulin, S. J., \& Puts, D. A. (2011). Voice correlates of mating success in men: examining "contests" versus "mate choice" modes of sexual selection. Archives of Sexual Behavior, 40(3), 551-557. doi:10.1007/s10508-010-9625-0.

Hodges-Simeon, C. R., Gurven, M., Cardenas, R. A., \& Gaulin, S. J. (2013). Voice change as a new measure of male pubertal timing: a study among Bolivian adolescents. Annals of Human Biology, 40(3), 209-219. doi:10.3109/03014460.2012.759622.

Hodges-Simeon, C. R., Gurven, M., Puts, D. A., \& Gaulin, S. J. (2014). Vocal fundamental and formant frequencies are honest signals of threat potential in peripubertal males. Behavioral Ecology, 25(4), 984 988. doi:10.1093/beheco/aru081. 
Hollien, H., Green, R., \& Massey, K. (1994). Longitudinal research on adolescent voice change in males. The Journal of the Acoustical Society of America, 96(5 Pt 1), 2646-2654.

Kindblom, J. M., Lorentzon, M., Norjavaara, E., Lonn, L., Brandberg, J., Angelhed, J.-E., et al. (2006). Pubertal timing is an indpendent predictor of central adiposity in young adult males. Diabetes, 55, 30473052. doi:10.2337/db06-0192.

Lam, T. H., Shi, H. J., Ho, L. M., Stewart, S. M., \& Fan, S. (2002). Timing of pubertal maturation and heterosexual behavior among Hong Kon Chinese Adolescents. Archives of Sexual Behavior, 31(4), 359366.

Lassek, W. D., \& Gaulin, S. J. C. (2009). Costs and benefits of fat-free muscle mass in men: relationship to mating success, dietary requirements, and natural immunity. Evolution and Human Behavior, 30, 322328.

Leongómez, J. D., Binter, J., Kubicová, L., Stolařová, P., Klapilová, K., Havlíček, J., et al. (2014). Vocal modulation during courtship increases proceptivity even in naive listeners. Evolution and Human Behavior, 35(6), 489-496. doi:10.1016/j.evolhumbehav.2014.06.008.

Mamun, A., Hayatbakhsh, M., O’Callaghan, M., Williams, G., \& Najman, J. (2009). Early overweight and pubertal maturation - pathways of association with young adults' overwieght: a longitudinal study. International Journal of Obesity, 33, 14-20.

Miner, E. J., Gurven, M., Kaplan, H., \& Gaulin, S. J. C. (2014). Sex difference in travel is concentrated in adolescence and tracks reproductive interests. Proceedings of the Royal Society B: Biological Sciences, 281(1796), doi:10.1098/rspb.2014.1476.

Negriff, S., \& Trickett, P. K. (2010). The relationship between pubertal timing and delinquent behavior in maltreated male and female adolescents. The Journal of Early Adolescence, 30, 518-542. doi:10.1177/ 0272431609338180.

Newman, S. R., Butler, J., Hammond, E. H., \& Gray, S. D. (2000). Preliminary report on hormone receptors in the human vocal fold. Journal of Voice, 14(1), 72-81.

Ostovich, J. M., \& Sabini, J. (2005). Timing of puberty and sexuality in men and women. Archives of Sexual Behavior, 34(2), 197-206.

Petersen, A. C., Crockett, L., Richards, M., \& Boxer, A. (1988). A self-report measure of pubertal status: reliability, validity, and intial norms. Journal of Youth and Adolescence, 17(2), 117-133.

Puts, D. A. (2010). Beauty and the beast: mechanisms of sexual selection in humans. Evolution and Human Behavior, 31, 157-175.

Puts, D. A., Gaulin, S. J. C., \& Verdolini, K. (2006). Dominance and the evolution of sexual dimorphism in human voice pitch. Evolution and Human Behavior, 27, 283-296.

Puts, D. A., Hodges, C., Cardenas, R. A., \& Gaulin, S. J. C. (2007). Men's voices as dominance signals: vocal fundamental and formant frequencies influence dominance attributions among men. Evolution and Human Behavior, 28, 340-344.

Puts, D. A., Apicella, C. L., \& Cárdenas, R. A. (2012a). Masculine voices signal men’s threat potential in forager and industrial societies. Proceedings of the Royal Society B: Biological Sciences, 279(1728), 601609. doi:10.1098/rspb.2011.0829.

Puts, D. A., Jones, B. C., \& DeBruine, L. M. (2012b). Sexual selection on human faces and voices. Journal of Sex Research, 49, 227-243.

Rhodes, G., Simmons, L. W., \& Peters, M. (2005). Attractiveness and sexual behavior: does attractiveness enhance mating success? Evolution and Human Behavior, 26, 186-201.

Schulz, K. M., \& Sisk, C. L. (2006). Pubertal hormones, the adolescent brain, and the maturation of social behaviors: lessons from the Syrian hamster. Molecular and Cellular Endocrinology, 254-255, 120-126.

Schulz, K. M., Molenda-Figueira, H. A., \& Sisk, C. L. (2009a). Back to the future: the organizationalactivational hypothesis adapted to puberty and adolescence. Hormones and Behavior, 55, 597-604.

Schulz, K. M., Zehr, J. L., Salas-Ramirez, K. Y., \& Sisk, C. L. (2009b). Testosterone programs adult social behavior before and during, but not after, adolescence. Endocrinology, 150(8), 3690-3698.

Seeman, E. (2001). Sexual dimorphism in skeletal size, density, and strength. The Journal of Clinical Endocrinology and Metabolism, 86(10), 4576-4584.

Seger, J. Y., \& Thorstensson, A. (2000). Muscle strength and electromyogram in boys and girls followed through puberty. European Journal of Applied Physiology, 81, 54-61.

Sell, A., Cosmides, L., Tooby, J., Sznycer, D., von Rueden, C., \& Gurven, M. (2009). Human adaptations for the visual assessment of strength and fighting ability from the body and face. Proceedings of the Royal Society B: Biological Sciences, 276(1656), 575-584. doi:10.1098/rspb.2008.1177.

Sell, A., Bryant, G. A., Cosmides, L., Tooby, J., Sznycer, D., von Rueden, C., et al. (2010). Adaptations in humans for assessing physical strength from the voice. Proceedings of the Royal Society B: Biological Sciences, 277(1699), 3509-3518. doi:10.1098/rspb.2010.0769. 
Shirtcliff, E. A., Dahl, R. E., \& Pollak, S. D. (2009). Pubertal development: corresondence between hormonal and physical development. Child Development, 80(2), 327-337.

Sisk, C. L., \& Zehr, J. L. (2005). Pubertal hormones organize the adolescent brain and behavior. Frontiers in Neuroendocrinology, 26(3-4), 163-174.

Snow-Harter, C., Whalen, R., Myburgh, K., Arnaud, S., \& Marcus, R. (1992). Bone mineral density, muscle strength, and recreational exercise in men. Journal of Bone and Mineral Research, 7, 1291-1296.

Stearns, S. C. (1989). Trade-offs in life-history evolution. Functional Ecology, 3(3), 259-268.

Titze, I. R. (2000). Principles of voice production. Iowa City, : National Center for Voice and Speech.

Tremblay, R. E., Schaal, B., Boulerice, B., Arseneault, L., Soussignan, R. G., Paquette, D., et al. (1998). Testosterone, physical aggression, dominance, and physical development in early adolescence. International Journal of Behavioral Development, 22, 753-777. doi:10.1080/016502598384153.

Vandenberg, S. G., \& Kuse, A. R. (1978). Mental rotations: a group test of three-dimensional spatial visualization. Perceptual and Motor Skills, 47, 599-604.

Voyer, D., Voyer, S., \& Bryden, M. P. (1995). Magnitude of sex differences in spatial abilities: a meta-analysis and consideration of critical variables. Psychological Bulletin, 117(2), 250-270.

Wakabayashi, A., Baron-Cohen, S., Wheelwright, S., Goldenfeld, N., Delaney, J., Fine, D., et al. (2006). Development of short forms of the Empathy Quotient (EQ-Short) and the Systemizing Quotient (SQShort). Personality and Individual Differences, 41(5), 929-940. doi:10.1016/j.paid.2006.03.017.

Walker, R., Gurven, M., Hill, K., Migliano, A., Chagnon, N., Souza, R. D., et al. (2006). Growth rates and life histories in twenty-two small-scale societies. American Journal of Human Biology, 18, 295-311. doi:10. 1002/ajhb.20510.

Wells, J. C. K. (2007). Sexual dimorphism of body composition. Best Practice \& Research Clinical Endocrinology \& Metabolism, 21(3), 415-430.

Weusthoff, S., Baucom, B. R., \& Hahlweg, K. (2013). The siren song of vocal fundamental frequency for romantic relationships. Frontiers in Psychology, 4, 439. doi:10.3389/fpsyg.2013.00439.

Wichstrøm, L. (2001). The impact of pubertal timing on adolescents' alcohol use. Journal of Research on Adolescence, 11(2), 131-150. doi:10.1111/1532-7795.00007.

Widen, E., Silvertoinen, K., Sovio, U., Ripatti, S., Cousminer, D. L., Hartikainen, A.-L., et al. (2012). Pubertal timing and growth influences on cardiometabolic risk factors in adult males and females. Diabetes Care, 35(4), 850-856.

Wills, T. A., Vaccaro, D., \& McNamara, G. (1994). Novelty seeking, risk taking, and related constructs as predictors of adolescent substance use: an application of Cloninger's theory. Journal of Substance Abuse, 6(1), 1-20. doi:10.1016/S0899-3289(94)90039-6.

Wilson, M., \& Daly, M. (1997). Life expectancy, economic inequality, homicide, and reproductive timing in Chicago neighbourhoods. BMJ, 314, 1271. doi:10.1136/bmj.314.7089.1271.

Witt, E. D. (2007). Puberty, hormones, and sex differences in alcohol abuse and dependence. Neurotoxicology and Teratology, 29(1), 81-95.

Wolff, S. E., \& Puts, D. A. (2010). Vocal masculinity is a robust dominance signal in men. Behavioral Ecology and Sociobiology, 64, 1673-1683. doi:10.1007/s00265-010-0981-5.

Zehr, J. L., Culbert, K. M., Sisk, C. L., \& Klump, K. L. (2007). An association of early puberty with disordered eating and anxiety in a population of undergraduate women and men. Hormones and Behavior, $52,427-435$. 